\title{
Fatores humanos aplicados a produtos de moda: materiais têxteis com termorregulação voltados ao público idoso
}

Human factors applied to fashion products: textile
materials with thermoregulation for the elderly public

Thiago Varnier ${ }^{1}$

Eugenio Andrés Díaz Merino ${ }^{2}$ 


\section{Resumo}

Os censos demográficos revelam o aumento do envelhecimento populacional, em vista disso, atender os idosos em relação ao seu vestuário requer considerar suas necessidades fisiológicas e promover estudos sobre fatores humanos, conforto e materiais têxteis. $\mathrm{O}$ estudo teve como objetivo identificar materiais têxteis para aplicação no vestuário de idosos com foco no conforto térmico. A metodologia se caracterizou como um estudo qualitativo exploratório observacional. A pesquisa permitiu identificar seis materiais têxteis com propriedade de termorregulação: HSG-2016, MERINO SPACER, MAFI 2018 08, TFIL $5318 B C, C 151150,80 M P E S / E N C H 180 P-$ CM/8OMPES e o sistema COOLMAX® ALL $S E A S O N$. Esses materiais utilizados em projetos de moda, proporcionam conforto e funcionalidade para o público idoso.

Palavras-chave: Idosos; fatores humanos; conforto térmico; materiais têxteis.

\section{Abstract}

Demographic censuses reveal an increase in the population aging. In order to meet the needs of the elderly in relation to their clothing it is necessary to consider their physiological needs and to promote studies on human factors, comfort and textile materials. The study aimed to identify textile materials for application in the clothing of elderly people focused on thermal comfort. The methodology was characterized as a qualitative exploratory observational study.The research allowed identifying six textile materials with thermoregulation properties: HSG-2016, MERINO SPACER, MAFI 2018 08, TFIL 5318 BC, C151150, 80MPES/ENCH180PCM/80MPES and the COOLMAX® ALL SEASON system. These materials used in fashion projects, provide comfort and functionality for the elderly public.

Key-words: Elderly; human factors; thermal comfort; textile materials

\footnotetext{
${ }^{1}$ Prof. UNOCHAPECÓ, Mestrando em Design - UFSC (thiagovarnier@unchapeco.edu.br)
}

${ }^{2}$ Prof. Dr. Universidade Federal de Santa Catarina - UFSC 


\section{Introducão}

O aumento da longevidade humana representa uma das maiores transformações e desafios da atualidade. Segundo previsões da Organização Mundial da Saúde (2015) ${ }^{1}$ daqui a 35 anos, o mundo terá o dobro de idosos que tem hoje. O órgão contabiliza cerca de 900 milhões de idosos atualmente, ou cerca de $12,3 \%$ da população total. A expectativa é de que em 2050 , representem $21,5 \%$, mais de um quinto do planeta (cerca de 2 bilhões).

No Brasil a população idosa irá mais do que triplicar até a metade deste século, saindo dos 20 milhões em 2010 para aproximadamente 65 milhões em 2050 (ANDRADE et al., 2013). A elevação do número de idosos no mundo, e mais precisamente no Brasil, representa uma influência para o estudo e desenvolvimento de uma moda direcionada ao público idoso, sendo este, um usuário que não é atendido pela maioria dos produtos. Os fatores associados ao processo de envelhecimento bem como as formas corporais, podem ser considerados como elementos de influência para projetos e pesquisas no desenvolvimento de uma moda diretamente relacionada para esse público.

Neste particular, observa-se uma escassez no mercado de moda específico para a terceira idade, que comtemple suas necessidades referentes aos fatores humanos, que impede a interação adequada entre usuários e produtos. De acordo com Gobbi, Reis e Bosse (2015) os idosos tem dificuldade em assumir qualquer fator que traga algum tipo de constrangimento ao mesmo. Portanto, é importante compreender o processo do envelhecimento e suas características, com a finalidade de conhecer as necessidades específicas, facilitando assim a interação dos idosos e vestuário.

A este respeito, Menegucci; Santos Filho, (2010), aborda que o processo de envelhecimento é inerente ao ser humano, o grau em que ocorrerá e seus efeitos variam em virtude dos fatores genéticos, da qualidade de vida e meio social. Assim, percebe-se que todo o ser humano em idade avançada pode apresentar dificuldades e características peculiares. Dessa maneira, ponderar os inúmeros aspectos do envelhecimento aos estudos referentes a moda, agrega aos produtos características funcionais, que melhoram a interface usuário versus vestuário.

Neste sentido, o usuário idoso, possui necessidades especificas com relação as suas vestimentas, devido a suas peculiaridades fisiológicas. Com o envelhecimento, a taxa metabólica basal diminui, ocorre a perda de tecido adiposo na camada de hipoderme e a microvasculatura mais esparsa e esgotada interferem na regulação eficaz da perda de calor, ou seja o corpo diminui a capacidade própria de regulagem de temperatura, fazendo com que os idosos sintam mais frio do que as pessoas jovens, dificultando as trocas de calor (SPIRDUSO, 2005; ARKING, 2008; MORELLI; REBELATTO, 2007). Dessa maneira cabe aos designers de moda compreender este con-

Informação contida no Relatório Mundial de Envelhecimento e Saúde. 2015. Disponivel em:< http://sbgg.org.br/wp-content/uploads/2015/10/OMS-ENVELHECIMENTO-2015-port.pdf > Acesso em: 01 abr.2017. 
texto e identificar as particularidades do público idoso no que se refere um projeto de vestuário direcionado ao conforto térmico.

Diante do exposto, os Fatores Humanos ou ergonomia, definida pela International Ergonomics Association (IEA, 2000) como uma disciplina científica preocupada com o entendimento das interações entre seres humanos e outros elementos de um sistema, aplica teorias, princípios, dados e métodos para projetar soluções na interface ser humano e sistema, de forma a tornálos compatíveis com as necessidades, capacidades e limitações das pessoas. Assim, a ergonomia pode servir de embasamento para outros campos do conhecimento, como é o caso do design aplicado a moda, propiciando o máximo de conforto, funcionalidade e eficácia no vestuário.

No que tange ao entendimento dos Fatores Humanos associados ao produto de moda, torna-se relevante pesquisar os materiais têxteis com propriedades termorreguladoras empregados no vestuário, com a finalidade de proporcionar conforto, usabilidade e bem estar dos idosos, afinal o vestuário vai além da estética, propiciando funcionalidade, agradabilidade e sensação de bem estar aos usuários.

Com base na problemática apresentada, este artigo tem como objetivo identificar materiais têxteis para aplicabilidade nas vestimentas dos idosos, com foco no conforto térmico. No que diz respeito à metodologia, classifica-se quanto à sua natureza como aplicada, pela abordagem qualitativa, exploratória e observacional. Quanto aos procedimentos técnicos à pesquisa divide-se em duas etapas: inicialmente uma pesquisa bibliográfica para o levantamento da fundamentação teórica e posteriormente uma pesquisa de campo, para o desenvolvimento da pesquisa, realizada na Feira Brasileira de Indústria Têxtil-FEBRATEX. A mesma aconteceu entre os dias 09 e 12 de agosto de 2016, no Parque Vila Germânica, na cidade de Blumenau, Santa Catarina (SC), apresentando os últimos lançamentos de máquinas, materiais e tecnologias para a indústria têxtil. A escolha dessa Feira, justifica-se por ser considerada a maior feira para a Indústria Têxtil das Américas, e conta com mais de 96 mil profissionais de todo o Brasil e de países como Alemanha, Argentina, Áustria, Bolívia, Chile, Cingapura, Colômbia, Coréia, Estados Unidos, Guatemala, Paraguai, Peru e Turquia (FEBRATEX, 2017).

A escolha dessa temática, justifica-se em virtude da escassez de publicações cientificas que abordam a problemática, bem como a constante evolução da indústria têxtil para utilizar a tecnologia com o intuito de criar materiais compatíveis ao estilo da vida moderna. Esses estudos e avanços tecnológicos tem provocado inserção tecnológica nos materiais têxteis e na moda. Dessa maneira, percebe-se que os novos materiais contribuem para alcançar os requisitos de conforto no vestuário, privilegiando a saúde dos usuários. 


\section{Fundamentação teórica}

\subsection{Envelhecimento humano e seus aspectos fisiológicos}

Para Farinatti (2008), existe uma variedade de definições que caracteriza o envelhecimento, dependendo da perspectiva escolhida como referência, sendo que as principais buscam explicá-lo pelo viés biológico e adaptativo. $O$ autor ainda afirma que $o$ envelhecimento é a consequência das modificações fisiológicas e bioquímicas devidas à ação do tempo sobre os seres vivos.

Segundo Spirduso (2005, p.6), envelhecimento refere-se a "um processo ou conjunto de processos que ocorrem em organismos vivos e que com o passar do tempo levam a uma perda da adaptabilidade, deficiência funcional, e, finalmente, à morte". Essa autora define o envelhecimento por meio dos processos fisiológicos em crescimento e desenvolvimento.

Convém destacar, que referir-se ao envelhecimento, sugere-se entender os vocábulos sobre envelhecimento, ou seja, o que é senescência e senilidade. Segundo estudos desenvolvidos por Vieira (2004, p. 290), senescência é o "processo de envelhecimento que resulta do somatório de alterações orgânicas, funcionais e psicológicas próprias do envelhecimento normal". A mesma autora relata que senilidade "define uma velhice patológica caracterizada por disfunções orgânicas, modificações somáticas limitantes, debilitação psíquica e enfraquecimento cerebral" (VIEIRA, 2004, p. 290).

De acordo com lida e Guimarães (2016, p. 688) "esses diversos sintomas de senilidade não ocorrem uniformemente para todas as funções fisiológicas e devem ser vistos como uma das faces das diferenças individuais entre as pessoas." Anjos et al. (2014, p.40) afirmam que "o ser humano, no decorrer da sua vida, está sujeito a alterações físicas e fisioló $g$ gicas que resultam em déficits físicos, cognitivos e comportamentais."

Segundo Morelli e Rebelatto (2007) com o envelhecimento, a pele fica menos elástica, devido a alteração da elastina e assim ocorre diminuição da espessura da pele e do tecido subcutâneo, levando o aparecimento de rugas. Neste mesmo sentido, Spirduso (2005), afirma que a pele é a grande reveladora do envelhecimento, pois torna-se fina, pálida, menos elástica e moldável, menos eficiente na termorregulação, com menor capacidade de produzir suor, e de exibir resposta inflamatória, sendo grande parte dessas mudanças causadas pela diminuição da circulação para a derme.

A este respeito, Arking (2008), assinala que a atrofia da camada da hipoderme é um dos fatores que torna mais difícil aos idosos a modulação da perda de calor. Dessa forma "a perda de tecido adiposo na camada de hipoderme e a microvasculatura cada vez mais esparsa e esgotada são os dois fatores relacionados a idade que interferem na regulação eficaz da perda de calor" (ARKING, 2008, p. 166).

Quando refere-se a termorregulação, lida e Guimarães (2016), afirmam que o ser humano é um animal homeotérmico, ou seja, sua temperatura corporal interna é mantida quase constante, a aproximadamente $37^{\circ} \mathrm{C}$, por mecanismos de termorregulação. "A temperatura corporal interna (...) pode oscilar em torno de $37 \pm 2^{\circ} \mathrm{C}$, ou seja, entre $35^{\circ} \mathrm{C}$ e $39^{\circ} \mathrm{C}$. Fora essa faixa indica alguma anormalidade. Temperaturas abaixo de $35^{\circ} \mathrm{C}$ e acima de $42^{\circ} \mathrm{C}$ podem tornar-se fatais" (IIDA; GUIMARÃES, 2016, p.378-379).

Os dados fornecidos por Arking (2008), apontam que na terceira idade, que é a faixa de idade acima dos 60 anos para os países em desenvolvimento e 65 anos nos 
países desenvolvidos, o corpo humano diminui a capacidade própria de regulagem de temperatura, fazendo com que os idosos sintam mais frio do que as pessoas mais jovens, dificultando as trocas de calor.

A partir dessas definições, percebe-se que os fatores intrínsecos do envelhecimento proporcionam ao design e a moda, um campo fértil de pesquisa, o que abre a de mais necessidade de pesquisas por parte de profissionais das diversas áreas do conhecimento, sociais, saúde, engenharia, tecnologia ou mesmo humanas, com a finalidade de encontrar soluções criativas para novos projetos que combinem inclusão, usabilidade e funcionalidade, associando sempre os fatores humanos.

\subsection{Fatores Humanos e sua aplicação ao produto de moda}

A associação brasileira de ergonomia (ABERGO, 2013), considera o termo Fatores Humanos como sinônimo de Ergonomia. Segundo a associação, ergonomia (ou Fatores Humanos) é uma disciplina científica relacionada ao entendimento das interações entre o seres humanos e outros elementos ou sistemas, e à aplicação de teorias, princípios, dados e métodos a projetos afim de otimizar o bem-estar humano e o desempenho global do sistema.

A partir desta constatação pode-se perceber que os Fatores Humanos é uma área de conhecimento multidisciplinar que visa adequar desde as ferramentas e ambientes de trabalho, até os produtos de uso pessoal, com a finalidade de alcançar a melhor integração entre o produto e seus usuários, no contexto da tarefa (trabalho) que deve ser desempenhada.

Isto posto, é possível deduzir que os Fatores Humanos deveriam ser requisitos obrigatório na concepção de um produto de moda, tornando seguro, prático, confortável e de fácil manejo, afinal este produto, mantém uma efetiva relação de uso com o ser humano. Hoje, introduzir os Fatores Humanos no vestuário é algo indiscutível, principalmente quando se trata da saúde do ser humano, visto que estes devem ser introduzidos na fase de concepção do produto. Conforme Löbach (2001), as funções de um produto podem ser classificadas como funções práticas, simbólicas e estéticas. Neste sentido o autor afirma que a função prática estaria relacionada a repercussões de natureza fisiológica, a função simbólica envolveria os aspectos culturais, pois abrange os valores e símbolos partilhados socialmente, e a função estética está associada à percepção.

Segundo lida e Guimarães (2016), as qualidades de um produto dentro da perspectiva dos Fatores Humanos estão relacionadas com vários aspectos que possuem por objetivo satisfazer as necessidades humanas, ou seja, para que os produtos funcionem bem em suas interações com os seus usuários, se faz necessário a qualidade técnica, usabilidade e agradabilidade.

A qualidade técnica, caracteriza-se pelo funcionamento e eficiência do produto. A usabilidade e a agradabilidade são as duas qualidades que se relacionam mais diretamente com os Fatores Humanos. A usabilidade é a qualidade ergonômica que permite adequação entre usuário e produto, facilitando movimentação (biomecânica e cognição), conforto (práticas de uso), facilidade de uso e segurança. Enquanto a agradabilidade relaciona-se com as preferências e gostos pessoais, relacionada ao fator estético 
onde é baseada nas reações emocionais, que proporcionam prazer ao consumidor, tornando os produtos visualmente agradáveis (IIDA; GUIMARÃES, 2016).

Em face disso, percebe-se a necessidade de ressaltar como princípio aplicável, qualidades técnicas e ergonômicas aos produtos de moda, as quais foram foco principal desta pesquisa, porém convém destacar, que a agradabilidade é fundamental para o produto de moda. Assim, quando um vestuário não está apropriado ao usuário, diante das questões relacionadas as necessidades do bem-vestir e as sensações de conforto, comprometem-se também a qualidade estética do produto, ou seja, a agradabilidade. Sendo assim, o conforto deve ser um aspecto cada vez mais associado ao produto têxtil.

\subsubsection{Os tipos de confortos aplicados ao produto de moda evidenciando o conceito do conforto térmico}

Originalmente, a palavra conforto deriva do vocabulário de origem latina confortare, que tem por significado fortificar, consolar (SCHIMID, 2005). Para Slater, o conforto é um "estado agradável de harmonia fisiológica, psicológica e física entre o ser humano e o ambiente" (SLATER, 1986, p.158). Dessa forma, o conforto deve ser o âmago do projeto referente ao produto de moda.

Para Slater, (1997), no vestuário, a visão de conforto total, pode ser dividida em quatro aspectos fundamentais:

- Conforto Sensorial de toque - conjunto de várias sensações neurais, quando um material têxtil entra em contato direto com a pele;

- Conforto Ergonômico- capacidade que uma peça de vestuário tem de "vestir bem" e de permitir a liberdade de movimentos do corpo.

- Conforto Psico-Estético- percepção subjetiva da avaliação estética, com base nos quatro sentidos humanos (visão, toque, audição e olfato), que contribuem para o bem estar total do usuário;

- Conforto Termofisiológico- estado térmico e de umidade à superfície da pele confortável que envolve a transferência de calor e de vapor de água por meio dos materiais têxteis ou do vestuário; (SLATER, 1997).

Diante do exposto percebe-se que o conforto sensorial de toque está relacionado com a maciez do tecido, resultado da sua composição. O conforto psico-estético é relacionado com o usuário, o qual percebe o tipo de material têxtil, a conformação da roupa ao corpo, a escolha das cores, e mesmo o odor de roupas usadas. Já o conforto térmico tem uma relação direta com as sensações de calor e frio, desse modo requer tecidos que proporcionem bem estar por meio de características naturais ou mesmo tecnológicas com fios de superfícies irregulares que facilite a circulação do ar. Em contrapartida o conforto ergonômico engloba todas as sensações acima, que agregadas à modelagem e a confecção de vestuário referente às necessidades especificas de cada indivíduo, permite o bem estar e a liberdade dos movimentos (VIANNA; QUARESMA, 2015).

De acordo com lida e Guimarães (2016), o conforto térmico é uma condição de equilíbrio térmico, ou seja, a soma da quantidade de calor gerado mais aquele ganho pelo organismo deve ser igual a quantidade de calor perdido para o ambiente, porém esse equilíbrio não é o suficiente para se garantir o conforto térmico, no qual o organismo é capaz de realizar várias combinações entre as variáveis ambientais e individuais, 
entretanto somente uma pequena faixa dessas variáveis são consideradas confortáveis.

Ainda, segundo lida e Guimarães (2016, p.386) "o conforto térmico depende também das condições ocasionais e preferencias individuais, sendo influenciado por fatores como: vestimenta (isolamento térmico) e intensidade do esforço físico (metabolismo)". Os vestuários ajudam a manter a temperatura corporal, dessa forma conservam o ar quente próximo a pele evitando a perda de calor, por convecção². Por outro lado, as roupas também absorvem o calor radiante do corpo.

Em relação as vestimentas como isolamento térmico, Wang et al. (2006) afirma que para o vestuário desempenhar uma função de proteção é necessário o equilíbrio entre as propriedades dos materiais utilizados, tais como a resistência térmica, caráter higroscópico, transferência da água além da permeabilidade ao vapor d'água. Broega e Silva (2010) salienta que o conforto percebido pelos usuários destes produtos depende, em grande parte, das propriedades sensoriais de toque e termofisiológicos dos tecidos, ou seja as propriedades físicas, térmicas e mecânicas.

Em face disso, é relevante entender o conceito de conforto térmico e sua abordagem na relação com a termorregulação dos idosos ao projetar vestuários funcionais. Segundo Broega e Silva (2010) o vestuário é uma barreira térmica entre o corpo humano e seu ambiente, onde um dos papéis funcionais do vestuário é manter o organismo num estado térmico confortável, qualquer que seja o ambiente exterior. Dessa maneira, abordar sobre os materiais têxteis que podem ser utilizados na confecção de vestuário para idosos, contribui positivamente a relação moda e corpo.

\subsection{Tecidos e Tecnologias têxteis}

Segundo Udale (2009) os tecidos são fundamentalmente feitos de fibras, sendo elas divididas em três categorias: naturais, artificiais ou sintéticas. As fibras naturais são derivadas de fontes orgânicas, de origem vegetal (composta de celulose), animal (composta de proteína) ou mineral. Como exemplos, pode-se citar o algodão, a seda, a lã, o couro, a pele e o metal. As fibras artificiais são feitas de fibras celulósicas e não celulósicas. A celulose é extraída de plantas e de árvores. Como exemplos de fibras artificiais celulósicas temos raiom, tencel, acetato, triacetato e lyocell, pois contêm celulose natural. As fibras não celulósicas, são consideradas sintéticas por serem totalmente fabricadas de substâncias químicas. São pouco respiráveis e menos confortáveis que as naturais, como exemplo, o acrílico e poliéster (UDALE, 2009).

Ainda baseado em Udale (2009) existem as microfibras que trabalham juntamente com a biotecnologia. Elas são produzidas com microcápsulas que contém substâncias químicas, como medicamentos, cremes, agentes antibacterianos, microrganismos que vivem de sujeira, bloqueadores UV, ou cheiros. Essas substâncias entram em contato com a pele por atrito ou em consequência do calor emitido pelo corpo, porém se esgotam ou saem gradualmente com a lavagem do tecido. As fibras podem ser utilizadas na produção de tecidos ou como revestimento de acabamento. Tecidos com essas propriedades são leves, aveludados, têm resistência ao vento e à água, e permitem a respirabilidade da pele (UDALE, 2009). Para o mesmo autor, a tecnologia vem sendo

2 A troca por convecção ocorre pelo movimento da camada de ar próxima à pele, que tende a retirar o ar quente (se a temperatura ambiental for abaixo de $37^{\circ} \mathrm{C}$ ) e substituí-lo por outro mais frio (IIDA; GUIMARÃES, 2016, p. 383).

Thiago Varnier

Eugenio Andrés Díaz Merino

HFD, v.6, n.11, p. 72-89, fev/jul 2017 
utilizada para gerar tecidos ou produzir novos tecidos de forma eficiente e rápida, com propriedades específicas no intuito de facilitar e melhorar a utilização e manutenção do vestuário por parte dos usuários.

De acordo com Pezzolo (2012) os novos tecidos além de não amarrotar e nem encolher oferecem outras vantagens como: cores inalteráveis, facilidade de lavagem, conforto, secagem rápida, capacidade de aquecer no frio, de resfriar no calor e de acelerar a troca térmica; capacidade de retirar o suor da parte interna da roupa e transporta-la para a parte externa muito rapidamente, o que mantém o corpo seco. Além de propriedades específicas: antimicrobiana, antiestética, fim das manchas, proteção solar (PEZZOLO, 2012).

Ainda segundo Pezzolo (2012) desde o início da década de 1990, inovações na área têxtil vem revolucionando a moda na virada do século, graças à alta tecnologia das tramas inteligentes. Como exemplo o tecido térmico, fabricado com base nas pesquisas espaciais da Nasa, é uma inovação que Carlos Miele ${ }^{3}$ utiliza em suas criações. Essa propriedade se deve à presença de microcápsulas de parafina. Quando a temperatura do corpo aumenta, a parafina se liquidifica e armazena o calor excessivo; quando a temperatura cai, ela se solidifica e libera o calor (PEZZOLO, 2012).

Segundo Menegucci e Santos Filho (2010) a indústria têxtil apresenta tecidos técnicos ou tecnológicos que agregam qualidades e desempenhos específicos voltado ao setor de roupas profissionais (bombeiros, militares, uniformes, etc) e as prática de esportes. Deve-se destacar que o avanço populacional da terceira idade e as projeções futuras são dados significantes de campo para aplicação destes tecidos, com o intuito de serem utilizados no cotidiano. Em suas pesquisas os autores abordam quatro empresas, duas nacionais (Santista Têxtil e Santaconstancia) e duas estrangeiras (Crailar Advanced Technologies e Polartec) que desenvolvem tecidos com propriedades funcionais e de possíveis aplicabilidades no vestuário do idoso. Porém foram identificados três tecidos na pesquisa de Menegucci e Santos Filho (2010), que possuem propriedades termorreguladoras, os quais são apresentados na tabela 1.

\begin{tabular}{|c|c|c|c|}
\hline Fabricante & Pais & Identificação & Caracteristicas \\
\hline Santaconstancia & Brasil & $\begin{array}{l}\text { Malha Take (fibra } \\
\text { de bambu e Lycra) }\end{array}$ & $\begin{array}{l}\text { Sensaçẫo de frescor e conforto térmico } \\
\text { que auxiliam na circulaçăo do ar interno, } \\
\text { excelente absorção de umidade e } \\
\text { ventilação evitando que a roupa fique } \\
\text { molhada. Sua microestrutura é capaz } \\
\text { de absorver e evaporar o suor } \\
\text { rapidamente. Fibra confortável no } \\
\text { verầ. }\end{array}$ \\
\hline Santaconstancia & Brasil & $\begin{array}{l}\text { Tafetá Cristal } \\
\text { (fibra de } \\
\text { bambu e } \\
\text { Lycra) }\end{array}$ & $\begin{array}{l}\text { Leve e compacto construido com } \\
\text { poliamida AMNI, proporciona conforto } \\
\text { termico, transferéncia rápida de calor e } \\
\text { umidade, fácil lavagem, rápida } \\
\text { secagem e năo precisa passar. Brilho } \\
\text { sutil, acabamento levemente } \\
\text { amassado. }\end{array}$ \\
\hline Polartec & $\begin{array}{l}\text { Estados } \\
\text { Unidos }\end{array}$ & X-Sensor & $\begin{array}{l}\text { Leve e adaptável a diferentes condiçðes } \\
\text { climáticas. Possui um sistema bi- } \\
\text { componente utilizando diferentes fibras } \\
\text { em cada lado do tecido, a interna } \\
\text { elimina o suor do contato com a pele e } \\
\text { a externa espalha a umidade. Utilizado } \\
\text { para agasalhos em individuos que } \\
\text { praticam esportes radicais e enfrentar } \\
\text { temperaturas extremas. }\end{array}$ \\
\hline
\end{tabular}

Fonte: os autores, com base em MENEGUCCI E SANTOS FILHO, 2010. 
Diante do exposto, pode-se ressaltar que todos os materiais têxteis apresentados na tabela 1 (Malha Take, Tafetá Cristal e X-sensor), são referências de tecnologias têxteis que podem ser aplicadas no desenvolvimento de um produto de moda vinculado ao público idoso. Para tanto, é importante conhecer as novas tecnologias referentes aos materiais têxteis, presentes atualmente, as quais podem ser utilizadas por profissionais de diversas áreas do conhecimento, de modo que possam contribuir na vida dos usuários.

\subsection{Síntese da fundamentação teórica}

$\mathrm{Na}$ fundamentação teórica apresentada foi possível compreender as necessidades específicas do público idoso, referente as alterações fisiológicas decorrentes do envelhecimento, ou seja, ocorre a atrofia da camada da hipoderme, a pele fica menos elástica e menos eficiente na termorregulação. Também, pôde-se perceber que a perda do tecido adiposo e a microvasculatura diminuem a capacidade própria de regulagem de temperatura, o que faz com que os idosos sintam mais frio que as pessoas jovens, e consequentemente necessitam de maior funcionalidade em seus vestuários, principalmente com relação ao conforto térmico. Em relação às contribuições dos Fatores Humanos para o design e a moda, percebeu-se que esta associação permite um produto seguro, prático e confortável que contribui com a saúde e bem estar dos usuários de modo a satisfazer suas necessidades com relação a qualidade técnica, usabilidade e agradabilidade. A abordagem dos tipos de confortos e principalmente o conforto térmico permitiu compreender as características funcionais do vestuário, que vão além de cobrir o corpo, permitem sensações de bem estar, conforto, liberdade de movimentos, bem como a maciez, a conformação adequada e composições funcionais. Contudo, percebeu-se também, que os materiais tecnológicos estão em constante evolução, com a finalidade de facilitar e melhorar a utilização e manutenção dos vestuários, bem como agregar propriedades funcionais, sejam elas, isolamento térmico, respirável, antibacteriano, facilidade de lavagem, conforto, proteção UV secagem rápida, entre outras, de maneira que estas, ofereçam benefícios na vida do ser humano.

\section{Procedimentos Metodológicos}

Buscando responder ao objetivo geral deste artigo, optou-se conduzir a pesquisa de natureza aplicada, pela abordagem qualitativa, exploratória e observacional. Para tanto, utilizou-se a estratégia de pesquisa de campo, realizada na Feira Brasileira para a Indústria Têxtil -FEBRATEX, no ano de 2016.

A pesquisa aplicada possui interesse prático e os resultados podem ser utilizados na solução de problemas (MARCONI; LAKATOS, 2011). Segundo Creswell (2010, p. 26) "a pesquisa qualitativa é um meio para explorar e entender o significado que os indivíduos ou grupos atribuem a um problema social ou humano". "A pesquisa exploratória é particularmente útil quando o responsável pelas decisões dispõe de muito poucas informações." (HAIR JR et. al., 2005). Assim a pesquisa desenvolvida pode ser considerada exploratória por ter sido realizada em um campo no qual há pouco conhecimento

Thiago Varnier

Eugenio Andrés Díaz Merino

HFD, v.6, n.11, p. 72-89, fev/jul 2017 
acumulado e sistematizado. De acordo com os procedimentos técnicos, a pesquisa foi elaborada em quatro (4) fases, conforme pode ser observado na figura 1.

Figura 1: Metodologia proposta no estudo

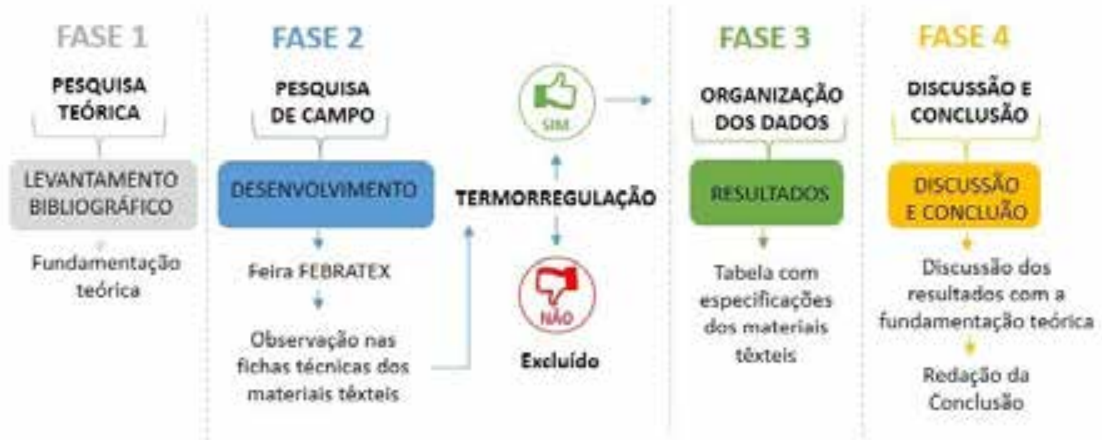

Fonte: os autores, 2017.

A primeira fase consistiu na pesquisa teórica onde foi realizado o levantamento bibliográfico, elaborado a partir de materiais já publicados em livros, artigos e periódicos. A segunda fase compreendeu o desenvolvimento da pesquisa, onde realizou-se a pesquisa de campo, que propôs à observação de fatos e fenômenos exatamente como ocorrem na realidade com o objetivo de extrair os dados e observações (GIL, 1991). Assim, a pesquisa de campo foi realizada na Feira FEBRATEX, no dia 10 de agosto de 2016, onde o pesquisador realizou observação individual dos estandes, analisando as fichas técnicas dos materiais têxteis. Nas especificações técnicas dos materiais foi identificada a presença de propriedades de termorregulação, em caso positivo os materiais eram registrados em uma planilha, em caso negativo, foram excluídos da análise.

Posteriormente, na terceira fase de organização dos dados coletados, foram organizados, classificados e hierarquizados por meio de uma tabela com as especificações dos materiais têxteis selecionados, identificando: fabricante, código de referência e materiais utilizados, sua funcionalidade e seus fatores de diferenciação. Por fim, na quarta fase, realizou-se a discussão dos resultados apresentados na tabela proposta com os dados obtidos na fundamentação teórica.

\section{Resultados}

Por meio da observação das empresas presentes na FEBRATEX, encontrou-se a INVISTA, com sua marca comercial, a LYCRA situada nos Estados Unidos e atualmente com franquia no Brasil. Verificou-se também o Centro Tecnológico (CITEVE) uma organização privada sem fins lucrativos, sediado em Vila Nova de Famalicão, em Portugal e com delegações comerciais no Brasil, Tunísia, Argentina, Paquistão, Chile e México.

A INVISTA trabalha em estreita colaboração com parceiros de negócios em toda a indústria para aproveitar o poder da marca $L Y C R A \circledR$ no intuito de diferenciar produtos e sinalizar a inovação em fibras e tecidos. Diante das observações nas especificações técnicas, verificou-se no estande da INVISTA, a nova tecnologia desenvolvida 
pela marca, o sistema COOLMAX® ALL SEASON, o qual afasta a umidade do corpo para manter o utilizador fresco e seco nos dias quentes, enquanto as estruturas de fibras proporcionam calor nos dias mais frios, ajudando a otimizar o desempenho.

De acordo com as informações presentes no site da CITEVE ${ }^{4}$, esta é uma organização de referência no panorama nacional e europeu, em matéria de promoção da inovação e desenvolvimento da Indústria Têxtil e do Vestuário, disponibilizando para as empresas um portfólio de serviços que inclui ensaios laboratoriais, certificação de produtos, consultoria técnica e tecnológica, I\&D + Inovação, formação, moda e design. A missão do CITEVE é "apoiar o desenvolvimento das capacidades técnicas e tecnológicas das Indústrias Têxtil e do Vestuário, por meio do fomento e da difusão da inovação, da promoção da melhoria da qualidade e do suporte instrumental à definição de políticas industriais para o setor" (CITEVE, 2017).

Diante disso, observou-se no estande da CITEVE, seis (6) empresas, que possuem tecidos com propriedades de termorregulação, sendo utilizados principalmente para práticas de esportes, proteção ao fogo, e temperaturas extremas. A tabela 2 aborda os seis (6) fabricantes encontrados na pesquisa de observação da FEBRATEX, bem como a referência, materiais utilizados, sua funcionalidade e fatores de diferenciação.

Tabela 2: Tecidos tecnológicos- fabricante, material utilizado, funcionalidade e fatores de diferenciação

\begin{tabular}{|c|c|c|c|}
\hline Fabricante & $\begin{array}{c}\text { Referência e } \\
\text { Material utilizado }\end{array}$ & Funcionalidade & $\begin{array}{c}\text { Fatores de } \\
\text { diferenciação }\end{array}$ \\
\hline 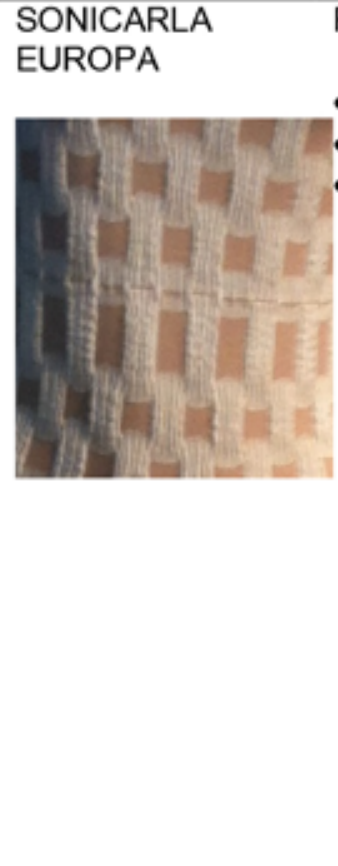 & $\begin{array}{l}\text { Ref: HSG-2016 } \\
\begin{array}{l}\text { - Poliamida; } \\
\text { - } \\
\text { Polipropileno; } \\
\text { Elastano. }\end{array}\end{array}$ & $\begin{array}{ll}\text { - } & \text { Respirável; } \\
\text { - } & \text { Antibacteriano; } \\
\text { - } & \text { Termorregulação; } \\
\text { - } & \text { Super elástico; } \\
\text { - } & \text { Alta tenacidade. }\end{array}$ & 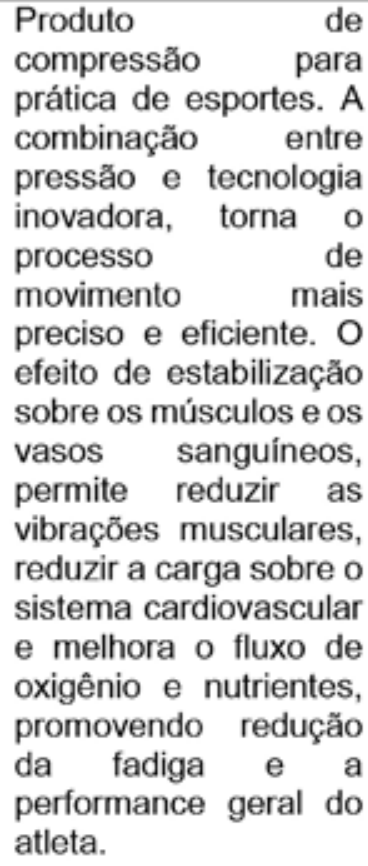 \\
\hline
\end{tabular}




\begin{tabular}{|c|c|c|c|}
\hline $\begin{array}{l}\text { A. SAMPAIO \& } \\
\text { FILHOS- Têxteis, } \\
\text { SA. }\end{array}$ & $\begin{array}{l}\text { Ref: } 61469-\text { Merino } \\
\text { Spacer } \\
\text { - } \quad 72 \% \text { Poliéster; } \\
\text { - } \quad 28 \% \text { Lã merino. }\end{array}$ & $\begin{array}{ll}\text { - } & \text { Respirável; } \\
\text { - } & \text { Secagem rápida; } \\
\text { - } & \text { Isolamento } \\
& \text { Térmico. }\end{array}$ & $\begin{array}{l}\text { Combinando esta } \\
\text { mistura de material } \\
\text { com a técnica de tricô } \\
\text { 3D, forma uma } \\
\text { camada externa e } \\
\text { outra interna. Isso } \\
\text { fornece isolamento } \\
\text { térmico ideal e boas } \\
\text { propriedades } \\
\text { mecânicas, } \\
\text { propiciando conforto } \\
\text { de uso. }\end{array}$ \\
\hline JOAPS- M & $\begin{array}{l}\text { Ref: MAFI } 201808 \\
\begin{array}{l}\text { - } \quad 96 \% \text { Poliamida; } \\
\text { - } \quad 4 \% \text { Elastano. }\end{array}\end{array}$ & $\begin{array}{ll}\text { - } & \text { Respirável; } \\
\text { - } & \text { Antibacteriano; } \\
\text { - } & \text { Secagem rápida; } \\
\text { - } & \text { Termorregulação; } \\
\text { - } & \text { Super elástico; } \\
\text { - } & \text { Proteção UV; } \\
\text { - } & \text { Limpeza fácil. }\end{array}$ & $\begin{array}{lr}\text { Malha produzida com } \\
\text { poliamida } & \text { Meryl. } \\
\text { Microfibras com } & \text { caracteristicas de } \\
\text { proteção UV } & \text { e } \\
\text { regulação } & \text { da } \\
\text { temperatura do corpo, } & \text { com máximo conforto. } \\
\text { Ação antibacteriana e } \\
\text { neutralização de de } \\
\text { odores. Toque fresco e } \\
\text { respirável. }\end{array}$ \\
\hline
\end{tabular}

\begin{tabular}{|c|c|c|c|}
\hline $\begin{array}{l}\text { TEARFIL Textile } \\
\text { Yarns by } \\
\text { Moretextile Group }\end{array}$ & $\begin{array}{l}\text { Ref: Tfil } 5318 \text { BC } \\
\text { 44\% Poliéster; } \\
28 \% \text { Lenzing Tencel } \\
\text { A100; } \\
28 \% \text { Polipropileno } \\
\text { Purelon. }\end{array}$ & $\begin{array}{l}\text { - } \quad \text { Respirável; } \\
\text { - } \quad \text { Antibacteriano; } \\
\text { - } \quad \text { Secagem rápida; } \\
\text { - } \quad \text { Alta tenacregulação; } \\
\text { - } \quad \text { Leveza Extrema; } \\
\text { - } \quad \text { Limpeza Fácil. }\end{array}$ & $\begin{array}{l}\text { Fibra leve com } \\
\text { secagem rápida. } \\
\text { Possibilita tingimentos } \\
\text { parciais. A combinação } \\
\text { com a fibra celulósica } \\
\text { de origem botânica } \\
\text { Lenzing Tencel A100, } \\
\text { eleva as vantagens do } \\
\text { Purelon e permite a } \\
\text { sua gestão de } \\
\text { humanidade } \\
\text { responsabilidade, ao } \\
\text { mesmo tempo que } \\
\text { promove } \\
\text { desenvolvimento de } \\
\text { têxteis ambientalmente } \\
\text { sustentáveis. }\end{array}$ \\
\hline
\end{tabular}

\begin{tabular}{|c|c|c|c|}
\hline $\begin{array}{l}\text { Sindónios Malhas, } \\
\text { AS }\end{array}$ & $\begin{array}{l}\text { Ref: C151150 } \\
\text { 58\% CLY Tencel; } \\
\text { 26\% Poliéster; } \\
11 \% \text { Lã } \\
5 \% \text { EL }\end{array}$ & $\begin{array}{ll}\text { - } & \text { Respirável; } \\
\text { - } & \text { Secagem rápida; } \\
\text { - } & \text { Termorregulação; }\end{array}$ & $\begin{array}{l}\text { O tecido apresenta três } \\
\text { camadas, sendo uma } \\
\text { camada interna que } \\
\text { proporciona conforto e } \\
\text { permite a absorção de } \\
\text { umidade, uma camada } \\
\text { intermediaria que } \\
\text { armazena o calor e } \\
\text { melhora a evaporação; } \\
\text { e por fim uma camada } \\
\text { externa que permite a } \\
\text { respiração, a retenção } \\
\text { do calor e proporciona } \\
\text { conforto. }\end{array}$ \\
\hline
\end{tabular}




\begin{tabular}{|c|c|c|c|}
\hline Coltec & $\begin{array}{l}\text { Ref: 80MPES/ } \\
\text { ENCH180PCM/80M }\end{array}$ & - $\quad$ Termorregulação & $\begin{array}{l}\text { Estrutura } \\
\text { termorreguladora com }\end{array}$ \\
\hline & $\begin{array}{l}\text { PES } \\
\text { - } \quad \text { Tecido } \\
100 \% \text { poliéster; } \\
\text { - Enchimento } \\
100 \% \text { poliéster. }\end{array}$ & & $\begin{array}{l}\text { aplicação de } \\
\text { microcápsulas PCMs } \\
\text { por spray em apenas } \\
\text { um dos lados do } \\
\text { enchimento. }\end{array}$ \\
\hline
\end{tabular}

Fonte: os autores, 2017.

A partir dos dados observados na FEBRATEX, verificou-se a existência de (6) seis materiais têxteis (HSG-2016, MERINO SPACER, MAFI 2018 08, TFIL 5318 BC, C151150, 8OMPES/ENCH 180PCM/80MPES e o sistema COOLMAX® ALL SEASON) que possuem uma perspectiva de aplicação nos projetos de moda, adequados ao público idoso, possivelmente atendendo suas necessidades referentes ao conforto térmico.

\section{Discussão}

Com base nos resultados obtidos na pesquisa de campo, corrobora-se o que Udale (2009) e Menegucci e Santos Filho (2010) afirmam em relação a tecnologia estar sendo utilizada para gerar tecidos ou produzir tecidos de forma eficiente, com propriedades específicas no intuito de facilitar e melhorar a utilização do vestuário. Os resultados obtidos na pesquisa de campo podem ser aplicados nos projetos de moda, para o público idoso, visto a importância de suas funcionalidades e fatores de diferenciação.

Outro fator importante de citar é a necessidade dos idosos por vestimentas que proporcionem o conforto térmico, fato esse justificado nos estudos de Morelli e Rebelatto (2007), Spirduso (2005), Arking (2008), onde corroboram que os idosos sentem mais frio que os jovens. Os resultados obtidos identificaram seis (6) materiais têxteis de possíveis aplicabilidades no vestuário dos idosos com propriedades de termorregulação.

Nos estudos de Pezzolo (2012), é abordado o tecido térmico fabricado com base nas pesquisas espaciais da Nasa, que possui microcápsulas de parafina, ou seja quando a temperatura do corpo aumenta, a parafina se liquidifica e armazena o calor excessivo; quando a temperatura cai, ela se solidifica e libera o calor. Essa tecnologia pode ser corroborada com o tecido ENCH180PCM/80MPES, da empresa COL$T E C$, que utiliza uma estrutura termorreguladora com aplicação de microcápsulas de PCMs - (material com função de mudança de fase) que atuam como uma esponja, mantendo a temperatura do corpo em aproximadamente $28^{\circ} \mathrm{C}$.

De acordo com Udale (2009), Menegucci e Santos Filho (2010) e Pezzolo (2012), os novos tecidos possuem propriedade funcionais, como, facilidade de lavagem, observado nos tecidos MAFI 201808 e TFIL 5318 BC, secagem rápida, identificado nos tecidos MERINO SPACER, MAFI 2018 08, TFIL 5318 BC e C151150, e também a capacidade de aquecer no frio, propriedade está identificada em todos os materiais têx- 
teis abordados nos resultados. Ainda corroborasse as propriedades específicas como antibacteriano identificados nos tecidos HSG-2016, MAFI 201808 e TFIL 5318 BC, e proteção UV que foi identificado no tecido, MAFI 2018 08. Essas propriedades elencadas são fundamentais para o público idoso, afinal com o envelhecimento ocorre perda da adaptabilidade e deficiência funcional (SPIRDUSO 2005).

Em relação ao tecido HSG-2016, percebeu-se nos fatores de diferenciação que a combinação entre pressão e tecnologia inovadora possibilita melhora no fluxo sanguíneo dos atletas, o que poderia ser uma possibilidade para o público idoso, que segundo Arking (2008) a microvasculatura cada vez mais esparsa e esgotada e a perda do tecido adiposo são fatores que interferem na termorregulação. Ainda Spirduso (2005) afirma que com o envelhecimento ocorre diminuição da circulação para a derme. Assim esse novo têxtil poderia proporcionar além da termorregulação o bem estar para os idosos.

O conceito de conforto termofisiológico de Slater (1997), aborda o estado térmico e de umidade à superfície da pele confortável que envolve a transferência de calor e de vapor de água por meio dos materiais têxteis. Assim pode-se evidenciar a relevância do sistema COOLMAX® ALL SEASON, identificado na feira, o qual proporciona o conforto termofisiológico, afinal ele afasta a umidade do corpo para manter o utilizador fresco e seco nos dias quentes, enquanto as estruturas de fibras proporcionam calor nos dias mais frios.

A partir dos estudos de lida e Guimarães (2016) as qualidades de um produto, sejam elas, técnicas, usabilidade ou agradabilidade tem por objetivo satisfazer as necessidades humanas. Os novos materiais têxteis identificados na FEBRATEX, podem auxiliar no desenvolvimento de produtos de moda para o público idoso, nas premissas da funcionalidade (termorregulação, respirável), usabilidade (conforto, antibacteriano, proteção UV, secagem rápida, limpeza fácil) e agradabilidade (leveza, super elástico, alta tenacidade) afinal suas propriedades e fatores de diferenciação facilitam a movimentação, o conforto e a segurança.

Wang et al. (2006) afirmam que para o vestuário desempenhar uma função de proteção é necessário conhecer as propriedades dos novos materiais têxteis e Broega e Silva (2010) complementam que o conhecimento destas propriedades dos materiais têxteis e a correlação entre elas devem ser utilizados de modo a melhorar as condições de uso na sua aplicação. Assim ao realizar projetos de moda para o público idoso, com o intuito de proteção e funcionalidade, cabe aos designers de moda associarem cada vez mais os novos materiais têxteis aos produtos do vestuário, visto que os fatores de diferenciação podem agregar qualidades técnicas aos produtos.

\section{Conclusões}

Foram identificados seis (6) materiais têxteis de aplicabilidade no vestuário do público idoso, evidenciando principalmente o conforto térmico, bem como outras características de distintas especificações, como respirável, antibacteriano, secagem rápida, proteção UV, de fácil limpeza, leveza, que são favoráveis aos usuários. Neste sentido, os resultados da pesquisa indicam que os tecidos tecnológicos identificados são potencialmente usáveis para o produto de moda associado ao público idoso, 
afinal, como apresentado na fundamentação teórica, os idosos possuem necessidades específicas com relação às alterações fisiológicas próprias do envelhecimento, as quais, devem ser levadas em consideração no desenvolvimento de projetos de moda.

É possível afirmar que o vestuário desempenha um papel de destaque para o conforto do usuário. Diante disso, os resultados alcançados com a metodologia proposta, pressupõem que na produção de vestuário, deve-se considerar o usuário como o ponto de partida para o desenvolvimento dos produtos, afinal o produto de moda deve ser confortável e funcional. Portanto, para atender aos idosos em relação ao vestuário, é de suma relevância considerar suas necessidades, capacidades e limitações, ao projetar um produto de moda, associando materiais têxteis que propiciem conforto e funcionalidade. Dessa forma é possível melhorar as condições de uso e proporcionar maior desempenho sem causar danos, afinal o design é uma disciplina que tem por objetivo promover o bem estar das pessoas.

Os novos materiais têxteis identificados nesse artigo, apresentam relevância técnica, pois contribuem para os requisitos de projeto de moda, especialmente para idosos, quando envolvem o conforto térmico, o que possibilita desenvolver vestuários funcionais, favorecendo a qualidade de vida dos usuários. Outras contribuições que podem ser destacadas nesta pesquisa, são as contribuições cientificas e sociais, devido à exposição da favorável relação entre os temas abordados, como os materiais têxteis, conforto e os Fatores Humanos, que, associados ao produto de moda, resgatam a importância e relevância da moda e design para a sociedade.

Pesquisar sobre o conforto e materiais têxteis que podem ser utilizados na confecção dos produtos de moda favorece a relação entre moda e corpo. Logo, projetar um vestuário para o público idoso, associando resultados de pesquisas e avanços tecnológicos permite priorizar o caráter funcional do vestuário, contribuindo para as necessidades dos usuários, o que possibilita uma interação benéfica entre produto versus idoso, de modo que esta interface otimize o bem estar humano.

Convém destacar que os procedimentos metodológicos adotados nesta pesquisa foram capazes de contribuir positivamente para o seu desenvolvimento, oportunizando ao pesquisador o contato direto com os tecidos tecnológicos, além do registro em tempo real de informações, como, dados qualitativos e quantitativos de materiais têxteis, que auxiliaram no desenvolvimento da sistematização.

Por fim, sugere-se para futuros estudos, pesquisas envolvendo a problemática e ponderando os vários tipos de conforto, com o intuito de identificar novos materiais têxteis que venham auxiliar na qualidade de vida dos usuários, afinal, desenvolver produtos com funcionalidade, usabilidade e agradabilidade requer associar resultados de pesquisas com avanços da tecnologia e indústria têxtil.

\section{REFERÊNCIAS}

ABERGO. Associação Brasileira de Ergonomia. 2013. Disponível em: <http://www. abergo.org.br/internas.php?pg=o_que_e_ergonomia>. Acesso em: 28 abr. 2017.

ARKING, Robert. Biologia do envelhecimento: observações e princípios. Ribeirão Preto: FUNPEC, 2008. 
ANDRADE, Luana Machado et al. Políticas públicas para pessoas idosas no Brasil: uma revisão integrativa. Ciência e Saúde Coletiva, v. 18, n. 12, p. 3543-3552, 2013.

ANJOS, Thaiana Pereira dos et al. Usabilidade e Acessibilidade de Moodle: Recomendações para o Uso do Ambiente Virtual de Ensino e Aprendizagem pelo Público Idoso. Human Factors In Design, Florianópolis, v. 3, n. 5, p.01-20, 2014. Disponível em: <http://www.revistas.udesc.br/index.php/hfd/article/view/5604>. Acesso em: 03 jun. 2017.

BROEGA, Ana Cristina; SILVA, Maria Elizabete C. O conforto total do vestuário: design para os cinco sentidos. Atas de Diseño, v. 5, n.9, p.59-64, 2010. 2010.

CITEVE. Sobre o CITEVE. Disponível em: http://www.citeve.pt/artigo/sobre_nos> Acesso em: 16 abr.2017.

CRESWELL, John W. Projeto de pesquisa: Métodos qualitativo, quantitativo e misto. 3 ed. Porto Alegre: Artmed, 2010.

FARINATTI, Paulo de Tarso Veras. Envelhecimento, promoção da saúde e exercício: bases teóricas e metodológicas, v. 1. São Paulo: Manole, 2008.

FEBRATEX. Disponível em:< http://febratex.fcem.com.br/informacoes/apresentacao-feira> Acesso em: 04.jun.2017.

GIL, Antonio Carlos. Como elaborar projetos de pesquisa. São Paulo: Atlas, 1991.

GOBBI, Aline Girardi; REIS, Alexandre Amorim dos; BOSSE, Michaelle. Ergonomia e usabilidade aplicados ao projeto de produtos focado no usuário idoso: a experiência do idoso com eletrodomésticos e mobiliários na cozinha. Human Factors In Design, Florianópolis, v. 3, n. 6, p.63-76, 2015. Disponível em: <http://www.revistas.udesc.br/ index.php/hfd/article/view/6070>. Acesso em: 04 jun. 2017.

HAIR JR, Joseph F. et al. Fundamentos em métodos de pesquisa em administração. Porto Alegre: Bookman, 2005.

IIDA, Itiro; GUIMARÃES, Lia Buarque de Macedo. Ergonomia: projeto e produção. 3. ed. São Paulo: Blucher, 2016.

INTERNATIONAL ERGONOMICS ASSOCIATION (IEA). The Discipline of Ergonomics. 2000. Disponível em:< http://www.iea.cc/whats/index.html> Acesso em: 15 abr.2017.

INVISTA. 2017.Disponível em:< http://www.invista.com/por/brands/coolmax.html> Acesso em: 23 abr.2017. 
LÖBACH, Bernd. Design Industrial: Bases para a configuração dos produtos industriais. São Paulo: Edgard Blucher, 2001.

MARCONI, Marina Andrade de; LAKATOS, Eva Maria. Fundamentos de metodologia científica. 6.ed., São Paulo, Atlas, 2011.

MENEGUCCI, Franciele; SANTOS FILHO, Abílio Garcia. Proteção e conforto: a relação entre os tecidos e o design ergonômico do vestuário para idosos. In: 9 CONGRESSO BRASILEIRO DE PESQUISA E DESENVOLVIMENTO EM DESIGN. Anais... São Paulo. p. 5343-5353, 2010.

MORELLI, José Geraldo da Silva; REBELATTO, José Rubens. Fisioterapia Geriátrica: A prática de assistência ao idoso. 2 ed. ampl. Barueri: Maonole, 2007.

ORGANIZAÇÃO MUNDIAL DA SAÚDE. Relatório Mundial de Envelhecimento e Saúde. 2015. Disponível em:< http://sbgg.org.br/wp-content/uploads/2015/10/OMS-ENVELHECIMENTO-2015-port.pdf > Acesso em: 01 abr.2017.

PEZZOLO, Dinah Bueno. Tecidos: história, tramas, tipos e usos. 3. ed. São Paulo: Senac São Paulo, 2012.

SLATER, k."The Assessment of Comfort", Journal Textile Institute, v. 77, n. 3, p.157$171,1986$.

SLATER, k." Subjective Textile Testing", Journal Textile Institute, v. 88 Part 1, n. 2, p. 79-91, 1997.

SPIRDUSO, Waneen Wyrick. Dimensões físicas do envelhecimento. Barueri: Manole, 2005.

UDALE, Jenny. Fundamentos do design de moda: tecidos e moda. Porto Alegre: Bookman, 2009.

VIANNA, Claudia; QUARESMA, Manuela. Ergonomia: conforto têxtil no vestuário do idoso. In: 15 ERGODESIGN- CONGRESSO INTERNACIONAL DE ERGONOMIA E USABILIDADE DE INTERFACES HUMANO-TECNOLOGIA. Anais... São Paulo: Blucher, v. 2, n. 1, p. 1662-1670, 2015.

VIEIRA, Eliane Brandão. Manual de Gerontologia: Um Guia Teórico-Prático para Profissionais, Cuidadores e Familiares. 2 ed. rev. atual. Rio de Janeiro: Revinter, 2004.

WANG, S. X.et al. Effect of phase - change material on energy consumption of intelligent thermal - protective clothing. Polymer Testing, v.25, n. 5, p.580-587, 2006. 